\title{
Keberhasilan Penetasan Telur Penyu Hijau (Chelonia mydas) Dalam Sarang Semi - Alami Dengan Kedalaman Yang Berbeda Di Pantai Sukamade, Banyuwangi, Jawa Timur
}

\author{
Edi Wibowo Kushartono, CB. Ronaldi Chandra E*, Retno Hartati \\ Departemen Ilmu Kelautan, Fakultas Perikanan dan Ilmu Kelautan, Universitas Diponegoro \\ JI. Prof. Soedarto, SH. Kampus UNDIP Tembalang, Semarang 50275 \\ Email: ronaldicb@gmail.com
}

\begin{abstract}
One of the conservation efforts undertaken to protect the green turtle (C. mydas L.) is by relocation of the nest where the eggs are removed from natural to semi-natural hatchery. The depth of proper needed to achieve the maximum level of hatching and emergence success. The purpose of this research that is to know the level of hatching catch and the emergence success of a nest at a different depth. The methods that used is an experimental research. Treatment that given is the different depth of nest with the green turtle as repetition. The depth of treatment is in $40 \mathrm{~cm}, 60 \mathrm{~cm}$, and $80 \mathrm{~cm}$, the amount of eggs is 30 eggs in each nest. Measurement and observation environmental conditions carried out during the incubation period. Observation the emergence of hatchlings started in day 50 of the incubation. Nest destruction was conducted on the 66th day incubation then eggs that failed to hatch were manually disected. The results showed that the levels of different depths does not effect the temperature inside the nest and hatching success, but the effect on the success rate of appearance. hatching success at all depths ranging between 93,33\% 94.44\% (the same height), but increasingly in the depth of the nest success rate of appearance tends to decrease. Figures shown good appearance at a depth of $40 \mathrm{~cm}$ (86.67\%), followed by 60 and $80 \mathrm{~cm}$ depth is $64.44 \%$ and $48.89 \%$ (sequential). The results of visual observations of the morphometry and performance lokomotori, hatchlings hatched at a depth of 60 and $80 \mathrm{~cm}$ better than hatchlings hatched at a depth of $40 \mathrm{~cm}$ both in the size and aggressiveness lokomotori swing flipper.
\end{abstract}

Keyword: hatching success, green turtle (Chelonia mydas L.), semi-natural hatchery

\begin{abstract}
Abstrak
Salah satu usaha konservasi yang dilakukan untuk melindungi Penyu hijau (Chelonia mydas L.) yaitu dengan tindakan relokasi yang mana telur dipindahkan dari sarang alami ke tempat penetasan semi alami. Kedalaman yang tepat dibutuhkan untuk mendapatkan tingkat penetasan dan keberhasilan kemunculan yang maksimal. Tujuan penelitian ini yaitu untuk mengetahui tingkat keberhasilan penetasan dan keberhasilan kemunculan pada kedalaman sarang yang berbeda. Metode yang dipakai dalam penelitian adalah experimental research dengan 3 perlakuan yaitu penanaman telur penyu hijau pada kedalaman 40, 60 dan $80 \mathrm{~cm}$, dengan kepadatan 30 butir telur setiap sarang. Pengukuran dan pengamatan kondisi lingkungan juga dilakukan selama masa inkubasi. Pengamatan munculnya tukik mulai dilakukan pada hari ke 50 masa inkubasi. Pembongkaran sarang dilakukan pada hari ke 66 masa inkubasi kemudian dilakukan pembedahan secara manual untuk mengamati telur yang gagal menetas. Hasil yang didapat menunjukkan bahwa tingkat kedalaman yang berbeda tidak berpengaruh terhadap suhu dalam sarang dan keberhasilan penetasan, tetapi berpengaruh terhadap tingkat keberhasilan kemunculan. Angka keberhasilan penetasan pada semua kedalaman berkisar antara 93,33\% - 94,44\% (sama-sama tinggi), namun semakin dalam tingkat kedalaman sarang tingkat keberhasilan kemunculan cenderung mengalami penurunan. Angka kemunculan yang baik ditunjukkan
\end{abstract}


pada kedalaman $40 \mathrm{~cm}(86,67 \%)$, diikuti kedalaman 60 dan $80 \mathrm{~cm}$ yaitu $64,44 \%$ dan 48,89\% (secara berurut). Hasil pengamatan secara visual terhadap morfometri dan performa lokomotori, tukik yang ditetaskan pada kedalaman 60 dan $80 \mathrm{~cm}$ lebih baik dibandingkan tukik yang ditetaskan pada kedalaman $40 \mathrm{~cm}$ baik dari ukuran maupun lokomotori agresifitas ayunan flipper.

Kata kunci: Keberhasilan penetasan, Penyu hijau, Semi alami

\section{PENDAHULUAN}

Penyu merupakan salah satu reptil terbesar yang hidup di laut dan mempunyai umur sampai ratusan tahun. Ada tujuh spesies penyu didunia, dan enam spesies diantaranya bertelur diperairan Indonesia. Jenis Penyu yang bertelur di Pantai Sukamade yaitu, Penyu Hijau, Penyu Lekang, Penyu Belimbing dan Penyu Sisik. Data yang terkumpul sejak tahun 1980 menunjukkan jenis penyu yang banyak mendarat dan melakukan peneluran adalah jenis Penyu Hijau.

Pemantauan populasi yang dilakukan secara intensif sejak tahun 1970 menunjukkan kecenderungan populasi yang semakin menurun (Dermawan et al., 2009). Fluktuasi pendaratan penyu hijau di Pantai Sukamade TNMB (Taman Nasional Meru Betiri) terjadi cukup signifikan, pada tahun 1994 dan 1997 mengalami jumlah pendaratan yang paling rendah yaitu secara berurut sebesar 260 dan 284 ekor. Pada tahun berikutnya secara berangsur mengalami kenaikan hingga pada tahun 2009 terhitung 1096 ekor, namun pada tahun 2010 kembali menurun terhitung 204 ekor (TNMB, 2011).

Pantai Sukamade, Kabupaten Banyuwangi dengan panjang garis pantai $\pm 3 \mathrm{~km}$ merupakan lokasi tempat bertelurnya penyu di kawasan TNMB, yang dikhususkan untuk menjadi sarang alami dari penyu yang bertelur. Di dalam pengelolaan Pantai Sukamade, dibentuk sebuah unit kerja yaitu Unit Pengelolaan Konservasi Penyu (UPKP) yang dilengkapi dengan ruang penetasan semi alami berupa bangunan dengan luas $\pm 120 \mathrm{~m}^{2}$ dengan atap berupa asbes.

Salah satu usaha konservasi yang dilakukan adalah dengan melakukan upaya pengamanan dan relokasi telur.
Kegiatan relokasi dilakukan setiap hari malam pada malam hari (20.00-00.00) WIB dan pagi hari (04.00-07.00) WIB secara rutin, kemudian telur-telur hasil pengamanan langsung ditanam di ruang penetasan dengan kedalaman $40-60 \mathrm{~cm}$.

Kedalaman sarang erat kaitannya dengan suhu dan keberhasilan penetasan. Semakin dalam sarang, maka suhu semakin tetap bila dibandingkan dengan suhu permukaan sarang, dan suhu pada bagian tengah sarang lebih tinggi di-bandingkan suhu pada bagian permukaan dan samping sarang (Nuitja, 1992). Semakin dalam sarang semakin besar pula energi yang dibutuhkan tukik yang menetas untuk merangkak dan sampai dipermukaan sarang, sehingga mempengaruhi tingkat keberhasilan kemunculan tukik tersebut.

\section{MATERI DAN METODE}

Materi penelitian ini berupa 270 butir telur yang diambil dari 3 induk penyu berbeda yang mendarat di sepanjang pantai Sukamade. Data yang didapatkan adalah data keberhasilan penetasan dan keberhasilan kemunculan menurut Miller (1999). Parameter lain yang diukur dalam penelitian ini adalah suhu sarang semi alami, masa inkubasi, hasil pembongkaran, kegagalan penetasan.

Metode yang digunakan adalah penelitian percobaan dengan pengamatan langsung dilapangan. Perlakuan yang di-gunakan dalam penelitian ini adalah tiga kedalaman sarang semi alami yang ber-beda, yaitu kedalaman 40, 60 dan $80 \mathrm{~cm}$, terhadap tiga induk yang berbeda sebagai pengulangan, sehingga secara keseluruhan berjumlah 9 buah sarang. Masingmasing sarang diisi dengan jumlah telur 30 butir setiap satu sarang. 


\section{Pengamatan Induk Penyu}

Penelitian diawali dengan kegiatan pengamatan terhadap induk penyu yang bertelur di sarang alami. Pengamatan bertujuan untuk memperoleh telur penyu hijau yang akan diujikan, data tentang induk dan mengetahui proses yang dilakukan oleh induk penyu. Pendataan terhadap induk meliputi pencatatan nomor tagging, panjang dan lebar karapaks penyu hijau, kedalaman sarang alami.

\section{Pemindahan Telur dari Sarang Alami ke Sarang Semi Alami}

Metode yang digunakan dalam memindahkan telur adalah metode transinkubasi, yaitu pemindahan telur- telur dari sarang alami ke dalam sarang semi alami. Telur penyu diangkat dari dalam sarang menggunakan tangan setelah diketahui induk selesai bertelur. Tanpa menghilangkan lendir dan pasir yang menempel pada cangkang, telur yang didapat dari masing- masing induk di tempatkan pada wadah (karung) yang berbeda. Telur- telur tersebut kemudian di bawa ke ruang penetasan sarang semi alami permanen yang ternaungi secara penuh, yang merupakan fasilitas Resort Sukamade.

\section{Penanaman Telur}

Penanaman telur dilakukan di ruang penetasan semi alami dengan letak dan posisi sarang mengikuti alur penanaman yang dilakukan dan ditentukan oleh pihak pengelola. Bentuk sarang semi alami dibuat menyerupai sarang alami yaitu berbentuk seperti labu ukur dengan lebar mulut sarang $\pm 20 \mathrm{~cm}$ dengan kedalaman sesuai dengan perlakuan yang diujikan, yaitu $40 \mathrm{~cm}$ (perlakuan 1), $60 \mathrm{~cm}$ (perlakuan 2), $80 \mathrm{~cm}$ (perlakuan 3). Setelah pembuatan sarang dengan kedalaman yang ditentukan selesai kemudian telur-telur diletakkan pada masing-masing sarang semi alami dengan kepadatan 30 butir setiap sarang. Penanaman telur dilakukan bersamaan dengan pipa PVC yang sebelumnya telah dimodifikasi dengan diberi lubang tambahan yang nantinya diposisikan diantara tumpukan telur dengan tujuan sebagai media bantu alat pengukur suhu untuk merekam suhu didalam sarang tanpa menggali kembali sarang penetasan semi alami.

\section{Pemasangan Alat Pengukur Suhu}

Alat pengukur suhu yang digunakan adalah thermometer digital yang dilengkapi dengan kabel sensor dengan sensor panas diujung kabelnya. Sensor panas yang berada diujung kabel thermometer dimasukkan kedalam sarang melalui mulut pipa PVC dan diposisikan berada tepat di lubang bantuan (modifikasi), kemudian dibiarkan tertanam dalam sarang selama antara 7-10 menit. Pencatatan suhu di lakukan bila suhu yang diperlihatkan oleh citra digital dari thermometer menunjukkan suhu yang stabil.

\section{Pengamatan Suhu Sarang Penetasan}

Pengamatan sarang semi alami dialkukan setiap hari terhadap suhu dalam sarang semi alami. Pengambilan data dilakukan empat kali dalm satu hari, yaitu pagi (06.00), siang (12.00), sore (18.00), dan malam (00.00).

\section{Masa Inkubasi}

Masa inkubasi dihitung dari saat telur ditanam pada sarang semi alami sampai munculnya tukik yang pertama keluar di permukaan sarang.

\section{Pembongkaran Sarang}

Pembongkaran sarang semi alami dilakukan pada 66 hari masa inkubasi. Pembongkaran sarang dilakukan pendataan dengan mengkategorikan isi dalam sarang yaitu $E$ (Emerged) = Tukik meninggalkan sarang, $S$ (Shells) = Jumlah cangkang telur kosong (kondisi $>50 \%$ sempurna), L (Live in nest) = Tukik hidup yang berhasil keluar dari cangkang (di dalam sarang), D (Dead in nest) = Tukik mati yang berhasil keluar dari cangkang (di dalam sarang), UD (Undeveloped) = Telur belum menetas dengan embrio yang tidak jelas. UH (Unhatched) $=$ Telur belum menetas jelas ada embrio, UHT 
(Unhatched term) = Embrio yang belum menetas yang tampaknya telah cukup usianya di dalam telur, $\mathrm{P}$ (Depredated) = Terbuka, cangkang hampir lengkap dengan terdapat sedikit sisa telur (oleh predator) (Miller, 1999).

\section{Analisa DataKeberhasilan Penetasan}

Keberhasilan Penetasan $(\%)=\frac{\text { Jumlah telur yang menetas }}{\text { Jumlah telur yang dinnkubasi }} x 100$

\section{Keberhasilan Kemunculan}

Keberhasilan Kemunculan $(\%)=\frac{\text { Jumlah tukik yang muncul }}{\text { Jumlah telur yang dinkubasi }} z 100$

\section{HASIL DAN PEMBAHASAN}

\section{Masa Inkubasi}

Hasil pengamatan masa inkubasi pada masing- masing perlakuan beda kedalaman menunjukkan angka yang tidak jauh berbeda. Rata- rata masa inkubasi, secara berurut pada kedalaman 80,60 , dan $40 \mathrm{~cm}$ memiliki masa inkubasi $64,64,3$ dan 64,7 hari. Masa inkubasi yang tidak jauh berbeda tersebut diduga dikarenakan oleh suhu sarang secara umum tidak jauh berbeda pada masingmasing kedalaman yang dapat dilihat dari rerata suhu sarang harian yaitu $28,07 \circ \mathrm{C}$ $(40 \mathrm{~cm}), 28,11^{\circ} \mathrm{C}(60 \mathrm{~cm})$ dan $28,05 \circ \mathrm{C}(80$ $\mathrm{cm})$. Hal ini sesuai dengan pendapat Du et.al. (2009) yang mengatakan suhu inkubasi yang relatif sama pada lapisan atas dan bawah sarang akan menghasilkan embrio yang menetas serentak.

Tabel 1. Masa Inkubasi.

\begin{tabular}{cccc}
\hline $\begin{array}{c}\text { Kedalaman } \\
(\mathrm{cm})\end{array}$ & Ulangan & $\begin{array}{c}\text { Masa } \\
\text { Inkubasi } \\
\text { (hari) }\end{array}$ & $\begin{array}{c}\text { Rata- } \\
\text { rata } \\
\text { (hari) }\end{array}$ \\
\hline \multirow{3}{*}{40} & 1 & 65 & \\
& 2 & 66 & 64,7 \\
60 & 1 & 63 & \\
& 2 & 62 & \\
& 3 & 66 & 64,3 \\
80 & 1 & 65 & \\
& 2 & 66 & 6 \\
& 3 & 65 & 64 \\
\hline
\end{tabular}

Pada masing-masing perlakuan beda kedalaman juga menunjukkan bahwa semakin dalam sarang, maka semakin lama jarak antara masa inkubasi ter-pendek dengan masa inkubasi terpanjang yaitu 3 hari $(40 \mathrm{~cm}), 4$ hari $(60$ $\mathrm{cm})$, dan 5 hari $(80 \mathrm{~cm})$. Hal ini diduga dikarenakan jarak tempuh pendakian kelompok tukik yang semakin panjang ,sehingga semakin dalam sarang semakin lama pula masa inkubasi yang dibutuhkan. Hasil tersebut selaras dengan pernyataan Dermawan (2009) dimana kelompok tukik mem-butuhkan waktu 2 hari atau lebih untuk mencapai permukaan pasir.

Lamanya masa inkubasi diduga turut dipengaruhi oleh keberadaan hama semut yang ditemukan pada saat memasuki minggu ke-8 dan pada tukik yang muncul kepermukaan sarang, yang diduga keberadaannya menghambat laju gerak tukik tersebut untuk sampai kepermukaan, bahkan dapat menyebabkan kematian masal pada kelompok tukik yang berusaha keluar sarang. Seperti yang dikatakan oleh Eckrich dan Owens (1995) yaitu selama inkubasi, keberadaan tukik dipengaruhi oleh faktor-faktor biotik, seperti predasi.

\section{Keberhasilan Penetasan dan Keberhasilan Kemunculan}

Tingkat keberhasilan penetasan pada masing masing kedalaman yaitu $94,44 \%(40 \mathrm{~cm}), 93,33(60 \mathrm{~cm})$ 94,44 (80 $\mathrm{cm})$. Tingkat keberhasilan penetasan yang tidak jauh berbeda diduga karena kondisi suhu pada masing-masing kedalaman tidak jauh berbeda dan masih termasuk dalam suhu yang toleran terhadap penetasan. Seperti yang dikatakan oleh Ackerman (1997) ketika diinkubasi pada suhu konstan, per-kembangan embrio penyu laut berada dalam kisaran suhu yang toleran dari $25-27^{\circ} \mathrm{C}$ hingga $33-35^{\circ} \mathrm{C}$, sedangkan jika di atas atau di bawah kisaran suhu tersebut, perkembangan embrio akan terganggu. Hasil ini selaras dengan yang dikatakan oleh Goin et. al. (1978) bahwa perkembangan suhu secara teratur dan bertahap pada batas- batas 
Tabel 2. Data Penetasan dan Kemunculan

\begin{tabular}{|c|c|c|c|c|c|c|c|c|c|c|c|}
\hline \multirow[t]{2}{*}{$\begin{array}{l}\text { Kedalaman } \\
\text { (cm) }\end{array}$} & \multirow[t]{2}{*}{ Ulangan } & \multirow[t]{2}{*}{$\begin{array}{l}\text { Jumlah } \\
\text { Telur (Butir) }\end{array}$} & \multicolumn{3}{|c|}{$\begin{array}{l}\text { Telur } \\
\text { Menetas } \\
\text { (Ekor) }\end{array}$} & \multicolumn{3}{|c|}{$\begin{array}{c}\text { Telur Gagal } \\
\text { Menetas } \\
\text { (Butir) }\end{array}$} & \multicolumn{3}{|c|}{ Keberhasilan (\%) } \\
\hline & & & $E$ & L & D & UD & $\mathrm{UH}$ & UHT & P & Menetas & Muncul \\
\hline \multirow{3}{*}{40} & 1 & 30 & 27 & 0 & 1 & 2 & 0 & 0 & & 93,33 & 90 \\
\hline & 2 & 30 & 22 & 0 & 5 & 0 & 2 & 1 & & 90 & 73,33 \\
\hline & 3 & 30 & 29 & 0 & 1 & 0 & 0 & 0 & & 100 & 96,67 \\
\hline \multirow[t]{2}{*}{ Rerata } & & & & & & & & & & 94,44 & 86,67 \\
\hline & 1 & 30 & 8 & 3 & 18 & 0 & 0 & 1 & & 96,67 & 26,67 \\
\hline \multirow[t]{2}{*}{60} & 2 & 30 & 24 & 0 & 2 & 3 & 1 & 0 & & 86,67 & 80 \\
\hline & 3 & 30 & 26 & 0 & 3 & 1 & 0 & 0 & & 96,67 & 86,67 \\
\hline \multirow[t]{2}{*}{ Rerata } & & & & & & & & & & 93,33 & 64,44 \\
\hline & 1 & 30 & 29 & 0 & 0 & 0 & 1 & 0 & & 96,67 & 96,67 \\
\hline \multirow[t]{2}{*}{80} & 2 & 30 & 27 & 0 & 21 & 2 & 0 & 0 & & 93,33 & 23,33 \\
\hline & 3 & 30 & 28 & 0 & 20 & 2 & 0 & 0 & & 93,33 & 26,67 \\
\hline Rerata & & & & & & & & & & 94,44 & 48,89 \\
\hline
\end{tabular}

Keterangan:

$E($ Emerged $)=$ Tukik meninggalkan sarang .

$\mathrm{L}$ (Live in nest) = Tukik hidup yang berhasil keluar dari cangkang (di dalam sarang).

$\mathrm{D}$ (Dead in nest) = Tukik mati yang berhasil keluar dari cangkang (di dalam sarang)

UD (Undeveloped) $=$ Telur belum menetas dengan embrio yang tidak jelas

UH (Unhatched) = Telur belum menetas jelas ada embrio.

UHT (Unhatched term) = Embrio yang belum menetas yang tampaknya telah cukup usianya di dalam telur.

$\mathrm{P}($ Depredated $)=$ Terbuka, cangkang hampir lengkap dengan terdapat sedikit sisa telur (oleh predator).

suhu yang baik akan menghasilkan laju tetas terbaik dan waktu pengeraman yang relatif singkat.

Tingkat keberhasilan kemunculan cenderung menurun pada setiap tingkatan sarang yang bertambah dalam. Diduga, tingkat kemunculan tukik yang rendah disebabkan oleh jarak antara dasar sarang menuju permukaan yang terlalu dalam sehingga energi tukik tidak cukup untuk mencapai permukaan. Hal ini dibuktikan dengan tingginya angka kematian tukik di dalam sarang terutama pada kedalaman $80 \mathrm{~cm}$ sebesar $45,55 \%$, yang lebih besar dibandingkan kedalaman lainnya. Temuan semut pada tukik yang muncul dan hasil pembongkaran sarang mengindikasikan adanya predasi (semut) seperti yang dikatakan Dermawan et.al. (2009) yang mengatakan kondisi tukik yang mati dengan kondisi melekat pada cangkang yang terbuka sebagian atau sempurna mengindikasikan adanya keberadaan predator.

Hasil pengamatan secara visual
terhadap tukik yang muncul ke permukaan terdapat perbedaan secara morfometri dan performa lokomotori tukik. Secara morfometri, tukik yang muncul dari sarang dengan kedalaman 60 dan $80 \mathrm{~cm}$ memiliki ukuran yang lebih besar dengan kondisi cadangan telur yang sudah hampir habis sepenuhnya dibandingkan tukik yang muncul dari kedalaman $40 \mathrm{~cm}$ yang memiliki ukuran tubuh lebih kecil dengan cadangan telur yang masih menonjol keluar dan terlihat berdenyut- denyut. Secara lokomotori, agresifitas ayunan flipper pada tukik yang muncul dari sarang dengan kedalaman 60 dan $80 \mathrm{~cm}$ cenderung lebih agresif dengan ayunan flipper yang cepat dan bertenaga, dibandingkan tukik hasil penetasan sarang dengan kedalaman $40 \mathrm{~cm}$ yang cenderung pasif dan ayunan flipper yang terlihat sangat lambat. Rowe (1997) mengatakan durasi (masa) dan intersitas suhu inkubasi akan memberikan efek secara komulatif terhadap fenotipe tukik berupa performa.

Berdasarkan data, intensitas suhu dan masa inkubasi dari setiap sarang tidak jauh berbeda, maka faktor tingkat kedalaman sarang diduga berpengaruh 
terhadap morfometri dan fenotip tukik. Diduga proses pendakian menuju permukaan pasir secara langsung melatih insting gerak tukik setelah menetas dan mempengaruhi laju metabolismenya sehingga kondisi cadangan makanan tukik telah hilang sebagian karena terkonversi menjadi tenaga dalam proses pendakian. Hal itu secara tidak langsung berpengaruh terhadap laju gerak (lokomotori) ayunan flipper dari tukik-tukik tersebut ketika sampai dipermukaan sarang.

Dengan menetaskan telur di sarang dengan kedalaman $40 \mathrm{~cm}$, akan dihasilkan tukik dengan cadangan makanan (energi) yang relatif lebih banyak sehinggga memungkinkan kelangsungan tukik tersebut sebelum mendapatkan makanan. Sedangkan pada kedalaman $\geq 60 \mathrm{~cm}$, akan menghasilkan tukik berukuran besar dengan ayunan flipper yang kuat, sehingga akan memungkinkan tukik terhindar dari predator saat berenang dilaut lepas.

\section{Kegagalan Penetasan}

Kegagalan penetasan merupakan dampak dari hasil proses penetasan yang tidak optimal, hal tersebut dapat dipengaruhi oleh banyak faktor. Baik faktor internal yaitu pada perkembangan telur itu sendiri, maupun faktor eksternal yaitu dari lingkungan disekitar telur.

Dari 270 butir yang digunakan, diketahui 254 butir $(94,07 \%)$ berhasil menetas dengan 16 butir (5,93\%) telur gagal menetas.Kegagalan telur hasil penetasan pada tabel 3 menunjukkan bahwa kategori UD (Undeveloped) mempunyai angka yang paling tinggi. Hal tersebut diduga karena adanya pengaruh gerakan berupa rotasi dan guncangan pada tahap awal perkembangan telur sehingga proses pembelahan terganggu dan tidak ada embrio yang terbentuk. Gerakan yang melibatkan rotasi dan atau mengguncang dari telur setelah fase perkembangan dapat menyebabkan pecahnya membran halus dan kematian pada embrio (Miller, 2003). Cangkang yang tidak berisi tukik dapat terjadi karena berbagai faktor alam. Salah satunya adalah adanya masalah dengan induk (infertile, gagal membelah dalam tahap diapause embrio setelah oviposisi), dan dampak biologis eksternal pada telur (predasi, invasi mikroba) (Limpus, 2008).

\section{Suhu Sarang Semi Alami}

Secara umum kondisi suhu sarang pada masing masing perlakuan di penetasan semi alami memiliki nilai yang tidak jauh berbeda antara sarang satu dengan lainnya, yang ditunjukkan oleh data rerata harian suhu sarang.

Rincian rata-rata suhu harian pada masing-masing kedalaman yaitu $28,07{ }^{\circ} \mathrm{C}$ $(40 \mathrm{~cm}), 28,11^{\circ} \mathrm{C}(60 \mathrm{~cm})$ dan $28,05{ }^{\circ} \mathrm{C}(80$ $\mathrm{cm})$. Meskipun terjadi fluktuasi suhu, tetapi tidak secara tajam dimana fluktuasi terbesar yaitu $0,47{ }^{\circ} \mathrm{C}$, sehingga masih dalam suhu yang toleran untuk suhu penetasan sehingga masa inkubasi dan laju tetas telur pada masing- masing kedalaman tidak jauh berbeda. Diduga ini dikarenakan penetasan dilakukan di ruang penetasan beratap (ternaungi) sehingga sinar matahari tidak langsung masuk tetapi melalui proses konduksi suhu ruang terhadap pasir. Ariane (1994) menyebutkan bahwa suhu yang dipancarkan oleh sinar matahari secara efektif diteruskan dalam proses radiasi, konveksi, konduksi melalui pasir ke tempat yang lebih dalam.

Selain terjadinya fluktuasi suhu, terjadi juga peningkatan suhu bersifat bertahap hingga terjadinya fase peningkatan suhu yang cukup signifikan, dimungkinkan fase ini merupakan fase embrionik dimana suhu sarang merupakan gabungan antara suhu pasir sarang dengan panas metabolisme telur.

Fase peningkatan suhu yang signifikan pada $\mathrm{Pl}$ dengan kedalaman 40 $\mathrm{cm}$ terjadi lebih lambat dua minggu dibandingkan dengan P2 $(60 \mathrm{~cm})$ dan P3 (80 cm), yaitu pada minggu ke-9, sedangkan P2 dan P3 sama- sama pada minggu ke-7 seperti yang ditunjukkan oleh Gambar 1. Hal ini diduga karena kedalaman $40 \mathrm{~cm}$ masih mendapatkan 


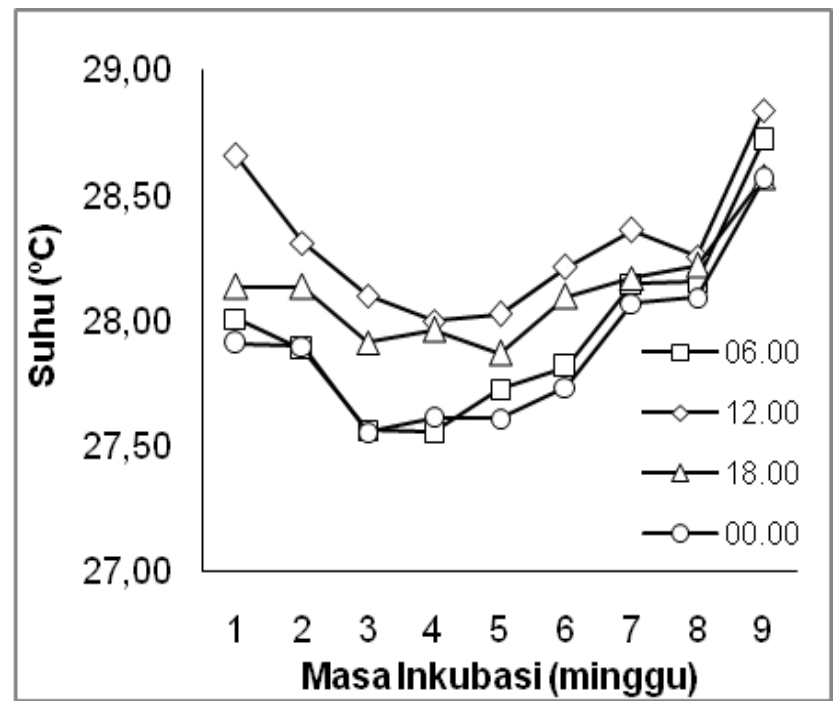

(a)

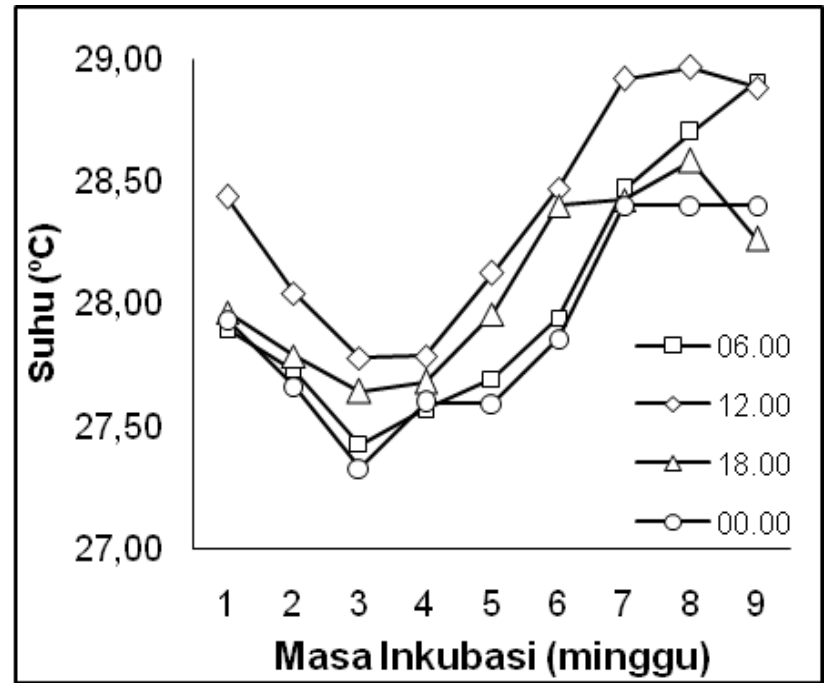

(b)

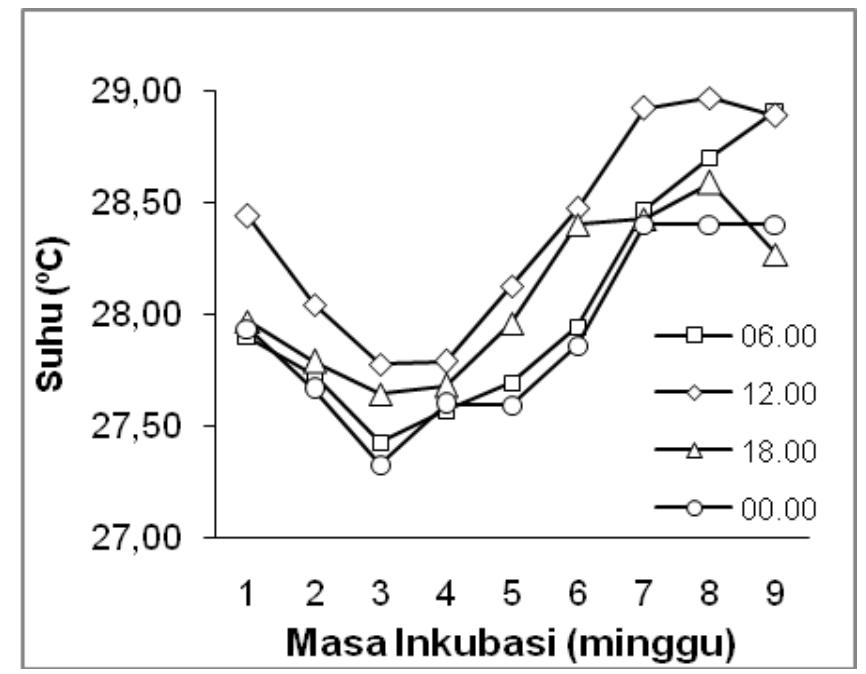

(c)

Gambar 1. (a) Grafik Suhu Sarang pada Kedalaman $40 \mathrm{~cm}$. (b) Grafik Suhu Sarang pada Kedalaman $60 \mathrm{~cm}$. (c) Grafik Suhu Sarang pada Kedalaman $80 \mathrm{~cm}$. 
pengaruh dari faktor luar seperti suhu saat sore hingga pagi hari yang cenderung rendah. Sedangkan pada kedalaman 60 $\mathrm{cm}$ dan $80 \mathrm{~cm}$ yang relatif stabil sehingga mempercepat laju proses embrionik.

\section{KESIMPULAN}

Berdasarkan hasil penelitian, tidak terdapat pengaruh yang besar oleh perbedaan kedalaman sarang terhadap terhadap suhu sarang dimana fluktuasi suhu yang terjadi masih dalam rentan suhu toleran untuk penetasan. Pada semua kedalaman sama-sama memiliki angka penetasan yang tinggi, yaitu $94,44 \%$ (40 $\mathrm{cm}), 93,33 \%(60 \mathrm{~cm})$ dan $94,44 \%(80 \mathrm{~cm})$. Kedalaman terbaik terjadi pada kedalaman $40 \mathrm{~cm}$ dimana angka kemunculannya tinggi yaitu $86,67 \%$.

\section{UCAPAN TERIMAKASIH}

Penulis mengucapkan terimaksih kepada Balai Taman Nasional Meru Betiri (TMNB) atas izin yang diberikan untuk melakukan penelitian, para petugas Resort Sukamade dan petugas Unit Pengelolaan Konservasi Penyu (UPKP) atas segala fasilitas dan bantuan yang diberikan, dan semua pihak yang telah banyak membantu yang tidak bisa disebutkan satu per satu.

\section{DAFTAR PUSTAKA}

Ackerman, R.A. 1997. The Nest Environment and The Embryonic Development of Sea Turtles. In: Peter L. Lutz, John A. Musick, and Jeanette Wyneken (Eds.). The Biology of Sea Turtles. Vol. II, CRC Press, $472 \mathrm{p}$.

Ariane, I. 1994. Studi Masa Inkubasi dan Keberhasilan Penetasan Semi Alami Telur Penyu Hijau (Chelonia mydas L.) di Pantai Sukamade, Taman Nasional Meru Betiri. [Skripsi]. Fakultas
Matematika dan IImu Pengetahuan Alam, Universitas Airlangga, Surabaya, 88 hlm. (Tidak Dipublikasikan).

Dermawan, A., Nyoman S. N., Dedi S., Matheus H.H., Mirza D.K., Syamsul B.L., Rofi A., M. Khazali., Mimi M., Poppi L., Wahjuhardini, Setiabudiningsih, dan Ali M., 2009. Pedoman Teknis Pengelolaan Konservasi Penyu. Direktorat Konservasi dan Taman Nasional Laut, Direktorat Jenderal Kelautan, Pesisir dan Pulau-Pulau Kecil, Departemen Kelautan dan Perikanan RI. Jakarta.

Du WG, Radder RS, Sun B, Shine R. 2009. Determinants of incubation period: do reptilian embryos hatch after a fixed total number of heart beats Journal of Experimental Biology 212:1302-1306.

Eckrich CE, Owens DW. 1995. Solitary versus arribadas nesting in the olive ridley sea turtles (Lepidochelys olivacea): a test of the predator-satiation hypothesis. Herpetologica. 51 (3): 349-354.

Goin, C.J, O.B. Goin and G.R. Zug. 1978. Introduction to Herpetology, Third Ed. W.E. Freeman and Co, San Fransisco.

Limpus, C.J. 2008. A Biological Review of Australian Marine Turtles Species. 2. Green Turtle, Chelonia mydas (Linnaeus). The Enviromental Protection Agency, Queensland, $74 \mathrm{p}$.

Miller, J.D., C.J. Limpus and M.H. Godfrey. 2003. Nest Site Selection, Ovipotision Eggs, Development, Hatching, and Emergence of Loggerhead Turtles. In: A. Bolten and B. Witherington (Eds.). Smithsonian Institution Press, Washington, DC, $125 \mathrm{p}$.

Rowe JW. 1997. Growth rate, body size, sexual dimorphism and morphometric variation in four populations of painted turtles (Chrysemys picta bellii) from Nebraska. American Midland Naturalist. 138 (1):174-188.

[TNMB] Taman Nasional Meru Betiri. 2011. Darmadja, B, N. Rohmah, A. A. Danu, dan Nugroho (Eds.). Buku Informasi Penyu Sukamade di Taman Nasional Meru Betiri 